\title{
USE OF VAGINAL MISOPROSTOL FOR CERVICAL RIPENING BEFORE HYSTEROSCOPY IN PERIMENOPAUSAL WOMEN
}

Jaya Chouydhary ${ }^{1}$, Veena Acharya ${ }^{2}$, Abhilasha Bansal ${ }^{3}$

\section{HOW TO CITE THIS ARTICLE:}

Jaya Chouydhary, Veena Acharya, Abhilasha Bansal. "Use of Vaginal Misoprostol for Cervical Ripening before Hysteroscopy in Perimenopausal Women". Journal of Evolution of Medical and Dental Sciences 2014; Vol. 3, Issue 05, February 03; Page: 1284-1290, DOI: 10.14260/jemds/2014/1981

ABSTRACT: OBJECTIVE: To evaluate the effectiveness of vaginal misoprostol for cervical priming before Diagnostic hysteroscopy in perimenopausal women. MATERIALS AND METHODS: Sixty women scheduled for hysteroscopy were randomly assigned to 2 groups. The study group $(\mathrm{n}=30)$ received $400 \mu \mathrm{g}$ of vaginal misoprostol $12 \mathrm{~h}$ before the procedure and the control group $(\mathrm{n}=30)$ without any drugs. The aim of study was to know the primary outcome i.e. the number of women who required cervical dilatation. Secondary outcome was cervical width (the largest size of Hegar dilator inserted without resistance as well as complications and adverse effects. RESULTS: Majority 26 $(86.6 \%)$ of women didn't required cervical dilatation in misoprostol group as compared to 4 (13.4\%) of women who required cervical dilatation in same group. However, majority $27(90 \%)$ of women required dilatation in control group. The association was highly significant statistically $\left(\mathrm{x}^{2}=20.314 \mathrm{P}\right.$ $<0.0001$ ).The largest size of Hegar dilator inserted without resistance was $8.0 \pm 0.5 \mathrm{~mm}$ in misoprostol group Vs. $5.5 \pm 1.2 \mathrm{~mm}$ in the control group $(\mathrm{p}<0.0001)$.The results were statistically significant. Uterine perforation occurred in 1 woman $3.3 \%)$ in the control group and none in misoprostol group. 9 women (30\%) experienced mild side effects like lower abdominal pain, fever and vaginal spotting after misoprostol application. CONCLUSIONS: We come to the conclusion by our study that the use of vaginal misoprostol is an effective cervical priming agent prior to Diagnostic hysteroscopy in perimenopausal women with minimal side effects. Misoprostol is a drug with low cost, easy application and is very useful for cervical priming.

KEYWORDS: Misoprostol, Hysteroscopy, Cervical priming.

INTRODUCTION: Due to increase in Life expectancy especially in this era about one third women spend their life during perimenopausal phase. During Perimenopausal period various changes like hot flushes, urogenital symptoms, mood changes and abnormal uterine bleeding may occur. In case of abnormal uterine bleeding it is important to visualize uterine cavity for proper diagnosis and management.

Hysteroscopy is a widely used method for direct visualization of uterine cavity and performing diagnostic procedure. Hysteroscopy has definite role in perimenopausal women for investigating abnormal uterine bleeding and to pinpoint the exact lesion in uterine cavity for diagnosis and management of patients.

For successful hysteroscopy we require cervical canal sufficiently dilated to allow the passage of hysteroscope. The procedure is difficult in perimenopausal \& post-menopausal women with small \& tight os. Hysteroscopy in this age group is associated with complications especially cervical tear, creation of false passage, uterine perforation, vasovagal reaction, pain \& inability to complete the 
procedure leading to failure. With the use of cervical priming agent it may be possible to perform hysteroscopy effectively without mechanical dilators. ${ }^{1}$

Misoprostol a synthetic prostaglandin E1 analogue has been used as an effective cervical ripening agent in pregnant women. However reports of its effectiveness in nonpregnant women to reduce complications of hysteroscopy related to cervical dilatation have shown conflicting results. ${ }^{2}$ Various studies showed different results for determining whether misoprostol is effective in cervical ripening in non-pregnant women especially after menopause. ${ }^{3}$

In our study we investigated the priming effect of vaginal misoprostol for cervical dilatation in perimenopausal \& postmenopausal women before hysteroscopy.

MATERIAL \& METHOD: The study was performed between July 2009 to December 2010 in the department of Obstetrics and Gynecology, Mahatma Gandhi Medical College and Hospital Jaipur.

The patients were recruited from Gynae OPD with complaint of abnormal uterine bleeding in perimenopausal age group (45-55yr). A total of 60 patients were taken and randomized to two groups. The study group $(n=30)$ received 400 microgram of misoprostol inserted vaginally in posterior fornix $12 \mathrm{hrs}$ prior to hysteroscopy. The control group $(\mathrm{n}=30)$ received placebo (vaginal tab) in the posterior fornix $12 \mathrm{hrs}$ prior to hysteroscopy. A detailed clinical history with clinical examination done. Ultrasonography was done in all women with abnormal uterine bleeding. Written consent was obtained from all patients. Proper counseling done regarding the Hysteroscopy. The Exclusion criteria were Known hypersensitivity or allergy to prostaglandins, cervical incompetence, cardiovascular disease, seizure disorder, liver disease, genital infections and cervical malignancy.

Hysteroscopy was done in both the groups of patients without general anesthesia. Under aseptic precaution, the baseline cervical dilatation was noted by passing Hegar dilator number 2 to 8 serially. The largest hegar dilator passed without resistance was recorded as mean cervical diameter. Subjective assessment of pain during dilatation using Visual Analog scale noted. Those patients who complained of moderate to severe pain (VAS score 5 or more) received either analgesia or anesthesia during further cervical dilatation. We also recorded the number of patients who required further dilatation of the cervix in both the groups for performing Hysteroscopy. Side effects including nausea, vomiting, diarrhoea, abdominal cramping, vaginal bleeding/spotting and headache were recorded. We also observed complications during the procedure-like cervical tear, false passage and uterine perforation in both groups.

RESULT: In our study the age distribution ranged from 45-55 years. The mean age among the misoprostol group was 47.23+/-2.38yrs and that among the placebo group was 46, 71+/-2.53yrs. Majority of the patients were of the age group 45-47 years both the groups were comparable with respect to age. (Table-1). 


\begin{tabular}{|c|c|c|c|}
\hline Age group (yrs.) & Study group & Placebo group & Total \\
\hline $45-47$ & 11 & 11 & 22 \\
\hline $48-50$ & 10 & 11 & 21 \\
\hline $51-53$ & 5 & 5 & 10 \\
\hline $54-55$ & 4 & 3 & 7 \\
\hline $\begin{array}{c}\text { Mean age in yrs. } \\
\text { +/-SD }\end{array}$ & $47.23+/-2.38$ & $46.71+/-2.53$ & \\
Table 1: Age distribution of the study population
\end{tabular}

The parity of the patients varied from Para 1 to Para 5. None of the patient was nulliparous in misoprostol group. Maximum number of patients were Para 3. In the study group 7 (23\%) patients had more than 3 children and in the control group 10 (33\%) patients had more than 3 children. (Table-2).

\begin{tabular}{|c|c|c|c|c|c|}
\hline \multirow{2}{*}{ Parity } & \multicolumn{2}{|c|}{ Misoprostol group } & \multicolumn{2}{|c|}{ Placebo Group } & Total \\
\hline & No. & $\%$ & No & $\%$ & \\
\hline 1 & 1 & $3.3 \%$ & 2 & $6.6 \%$ & 3 \\
\hline 2 & 8 & $26.6 \%$ & 6 & $20 \%$ & 14 \\
\hline 3 & 14 & $46.6 \%$ & 12 & $40 \%$ & 26 \\
\hline 4 & 5 & $16.6 \%$ & 9 & $30 \%$ & 14 \\
\hline 5 & 2 & $6.6 \%$ & 1 & $3.3 \%$ & 3 \\
\hline \multicolumn{7}{|c|}{ Table 2: Distribution of parity } \\
\hline
\end{tabular}

Menopausal women constituted $28.3 \%$ of the sample size, of these 9 were in study group and 8 in control group. (Table-3)In majority of women presenting with abnormal uterine bleeding the majority of women presented with menorrhagia in both misoprostol and placebo groups. Postmenopausal bleeding was present in 9 patients in misoprostol group and 8 patients in placebo group (Table-4).

\begin{tabular}{|c|c|c|c|}
\hline & Misoprostol group & Placebo group & Total \\
\hline Premenopausal & $21(70 \%)$ & $22(73.33 \%)$ & $43(71.66 \%)$ \\
\hline postmenopausal & $9(30 \%)$ & $8(26.66 \%)$ & $17(28.3 \%)$ \\
\hline TOTAL & 30 & 30 & $60(100 \%)$ \\
\hline
\end{tabular}

Table3: Distribution of perimenopausal women 


\begin{tabular}{|c|c|c|c|}
\hline Chief complaints & Misoprostol group & Placebo group & Total \\
\hline Menorrhagia & $12(40 \%)$ & $14(46.6 \%)$ & $26(43.33 \%)$ \\
\hline Polymenorrhagia & $5(16.6 \%)$ & $3(10 \%)$ & $8(13.33 \%)$ \\
\hline Menometrorrhagia & $3(10 \%)$ & $4(13.3 \%)$ & $7(11.66 \%)$ \\
\hline Post coital Bleeding & $1(3.3 \%)$ & $1(3.3 \%)$ & $2(3.33 \%)$ \\
\hline Post-menopausal bleeding & $9(30 \%)$ & $8(26.6 \%)$ & $17(28.33 \%)$ \\
\hline $\begin{array}{l}\text { Total } \\
\end{array}$ & 30 & 30 & \\
\hline
\end{tabular}

The baseline cervical in women with misoprostol group ranged from 4-8mm with the majority having baseline dilatation of $8 \mathrm{~mm}(60 \%)$ while the majority of women in the control group had baseline cervical dilatation of $2 \mathrm{~mm}(72 \%)$. Only $3(10 \%)$ women had dilatation of $6 \mathrm{~mm}$ which could be explained by their high parity. $(\mathrm{p}<0.001$ Highly significant)

In our study it was found that mean baseline dilatation among menopausal women was more in misoprostol group ( $5.77 \mathrm{~mm})$ as compared to placebo group $(2.25 \mathrm{~mm})$ which is statistically significant. Kant Anita et al ${ }^{1}$ also found similar results. About $44.4 \%$ women had baseline dilatation of $6 \mathrm{mmand} 22.2 \%$ women had dilatation of $8 \mathrm{~mm}$ in misoprostol group while 7 patients out of 8 (87.5\%) had baseline dilatation of $2 \mathrm{~mm}$ only in placebo group.(Table-5).

\begin{tabular}{|c|c|c|c|c|}
\hline $\begin{array}{c}\text { Baseline } \\
\text { dilatation }\end{array}$ & $\begin{array}{c}\text { Misoprostol group } \\
\text { Premenopausal } \\
\text { Menopausal }\end{array}$ & Total & $\begin{array}{c}\text { Placebo group } \\
\text { Premenopausal } \\
\text { Menopausal }\end{array}$ & Total \\
\hline $2 \mathrm{~mm}$ & 00 & $0(0 \%)$ & 147 & $21(70 \%)$ \\
\hline $4 \mathrm{~mm}$ & 13 & $4(13.3 \%)$ & 51 & $6(20 \%)$ \\
\hline $6 \mathrm{~mm}$ & 44 & $8(26.6 \%)$ & 30 & $3(10 \%)$ \\
\hline $8 \mathrm{~mm}$ & 162 & $18(60 \%)$ & 00 & $0(0 \%)$ \\
\hline Total & 219 & $30(100 \%)$ & 228 & $30(100 \%)$ \\
\hline
\end{tabular}

Table 5: Baseline cervical dilatation in Misoprostol and Placebo groups before Hysteroscopy

Barcaite et $\mathrm{al}^{4}$ reported that vaginal misoprostol applied before hysteroscopy reduced cervical resistance and the need for cervical dilatation in perimenopausal and postmenopausal women with only mild adverse effects

More side effects were seen in misoprostol group. 9out of 30 women suffered from mild side effects like lower abdominal pain ${ }^{5}$, vaginal spotting ${ }^{3} \&$ fever $^{1}$ but these were relatively mild in intensity none requiring additional treatment. There was no complication in misoprostol group related to cervical dilatation while in placebo group cervical tear occurred in 2 cases and uterine perforation in 1 case (Table-6). 4 cases (13.45\%) required further dilatation in the study group compared to $27(90 \%)$ in the control group (p<.001). (Table-7). 


\section{ORIGINAL ARTICLE}

\begin{tabular}{|l|l|l|l|}
\hline \multicolumn{1}{|c|}{ Side effects } & \multicolumn{1}{|c|}{ Group } & \multicolumn{1}{c|}{ Group } & \\
\hline & Misoprostol & Placebo & Total \\
\hline Nausea and vomiting & $2(6.6 \%)$ & $0(0 \%)$ & 2 \\
Lower abdominal pain & $5(16.6 \%)$ & $2(6.6 \%)$ & 7 \\
$\quad$ 3-Diarrhoea & $3(10 \%)$ & $0(0 \%)$ & 3 \\
4-Fever & $1(3.3 \%)$ & $0(0 \%)$ & 1 \\
Complications & $1(3.3 \%)$ & $2(6.6 \%)$ & 2 \\
5- cervical tear & $0(0 \%)$ & $1(3.3 \%)$ & 1 \\
6-False passage & 0 & $1(3.3 \%)$ & 1 \\
7- Uterine perforation & & & \\
\hline Total & $9(30 \%)$ & $3(10 \%)$ & \\
\hline \multicolumn{2}{|c|}{ Table 6: Side effects \& complications } \\
\hline \multicolumn{2}{|c|}{} \\
\hline
\end{tabular}

\begin{tabular}{|c|c|c|c|c|}
\hline & Misoprostol group & $\%$ & Placebo group & $\%$ \\
\hline Passage without Dilatation & 26 & $86.6 \%$ & 3 & $10 \%$ \\
\hline Passage with Dilatation & 4 & $13.4 \%$ & 27 & $90 \%$ \\
\hline Total & 30 & $100 \%$ & 30 & $100 \%$ \\
\hline
\end{tabular}

Table 7: Passage of Hysteroscope

Association between various factors and the passage of hysteroscope into the cervical canal in the group in which misoprostol was used for cervical ripening ( $t$ test). As the parity increases it was seen that the passage of hysteroscope is easier ( $p$ value- $<0.01$, significant) this is because of higher baseline dilatation in those with high parity along with combined effect of misoprostol. As the baseline dilatation increases the hysteroscope could be easily introduced into the cervical canal which is as expected ( $\mathrm{p}$ value $-<0.001$, highly significant). The mean baseline dilatation among misoprostol group at which it was easy to introduce the hysteroscope was $7.37 \mathrm{~mm}$ while at $4.26 \mathrm{~mm}$ it was not possible to introduce the hysteroscope without dilating the cervix. It was noted that baseline cervical dilatation is not affected by age.( $p$ value $>0.05$ ).

The utility of diagnostic hysteroscopy could be improved by facilitating its use in an office setting. One limiting factor is cervical dilation. If misoprostol could decrease or eliminate the need for the cervical dilatation, hysteroscopy could be accomplished more easily. We undertook this study to determine if the use of misoprostol would improve baseline cervical dilatation before diagnostic hysteroscopy and obviate the need for dilatation in perimenopausal and postmenopausal women presenting with abnormal uterine bleeding. Barcaite et $\mathrm{al}^{4}$ reported that vaginal misoprostol applied before hysteroscopy reduced cervical resistance and the need for cervical dilatation in perimenopausal and postmenopausal women with only mild adverse effects. Diagnostic hysteroscopy with or without directed biopsy is now considered gold standard in the workup of abnormal uterine bleeding among perimenopausal and postmenopausal women. Diagnostic hysteroscopy is minimally invasive intervention that can be used to diagnose many intrauterine and endocervical problems. 
Misoprostol for cervical ripening in perimenopausal and postmenopausal women to prevent cervical injury during dilatation is not well established.

In our study we have inserted $400 \mathrm{mcg}$ of misoprostol per vaginally $12 \mathrm{hrs}$. prior to hysteroscopy and it was found that misoprostol is an effective cervical ripening agent causing sufficient cervical dilatation for easy passage of hysteroscope without the need of mechanical dilation. We found that time interval of 12 hrs. after administration of misoprostol resulted in increased cervical dilatation and ease of further cervical dilatation if required. This is in agreement with other investigator $2,5,6$, 7. In majority of women in misoprostol group-86.6\%, the hysteroscope could be introduced into the cervical canal without any need for dilatation. In the control group $90 \%$ required dilatation while only in $10 \%$ the hysteroscope could pass without any mechanical dilatation. The pvalue for these observation was $<0.001$ which is significant.

From our study we come to the conclusion that Vaginal misoprostol is an effective cervical ripening agent prior to diagnostic hysteroscopy in perimenopausal\& postmenopausal women.

$90 \%$ women required dilatation in control group while only $13.4 \%$ women in misoprostol group required dilatation. The results were statistically significant in our study $(\mathrm{p}<0.001)$.The success rate of Misoprostol for ripening of cervix before hyeteroscopy in our study was $86.6 \%$. Misoprostol is a drug with low cost, easy application, with minimum side effects for cervical ripening.

\section{REFERENCES:}

1. Kant A, Divyakumar, Priyambada U. A randomized trial of vaginal misoprostol for cervical priming before hysteroscopy in postmenopausal women. J Mid-life Health 2011; 2:25-27.

2. Nagi SW, Chan YM, Liu KI, Ho PC. Oral misoprostol for cervical priming in non-pregnant women. Hum Reprod 1997; 12:2373-5.

3. Crane JMG, Healey S. Use of misoprostol before hysteroscopy: a systemic rewiew. J Obstet Gynaecol Can 2006; 28:373-9.

4. Barcaite E, Bartusevicius A, Railaite DR, Nadisauskiene R. Vaginal misoprostol for cervical priming before hysteroscopy in perimenopausal and postmenopausal women. Int J Gynaecol Obstet. 2005; 91(2):141-5. [PubMed]

5. Preutthipan S, Herabutya Y. Vaginal misoprostol for cervical priming before operative hysteroscopy: a randomized controlled trial. Preutthipan S, HerabutyaY. Obstet Gynaecol 2000;96:890-4

6. Oppegaard K S, Nesheim BI, Istre O, Qvigstad E. Comparison of self-administered vaginal misoprostol versus placebo for cervical ripening prior to operative hysteroscopy using a sequential trial design, BJOG.2007 Jun;114 (6):769, el-12.

7. Batukan C, Ozgun MT, Ozcelik B. Cervical ripening before operative hysteroscopy in premenopausal women: a randomized, double-blind, placebo-controlled comparison of vaginal and oral misoprostol, Fertil Steril.2008 Apr;89(4):966-73.Epub 2007 Aug 6. 


\section{ORIGINAL ARTICLE}

\section{AUTHORS:}

1. Jaya Chouydhary

2. VeenaAcharya

3. Abhilasha Bansal

\section{PARTICULARS OF CONTRIBUTORS:}

1. Professor, Department of Obstetrics \& Gynaecology, Mahatma Gandhi Medical College, Sitapura, Jaipur.

2. Professor, Department of Obstetrics \& Gynaecology, Mahatma Gandhi Medical College, Sitapura, Jaipur.

3. Resident, Department of Obstetrics \& Gynaecology, Mahatma Gandhi Medical College, Sitapura, Jaipur.

\section{NAME ADDRESS EMAIL ID OF THE} CORRESPONDING AUTHOR:

Dr. Jaya Chouydhary,

Professor,

Department of Obstetrics \&Gynaecology, Mahatma Gandhi Medical College,

Sitapura, Jaipur.

E-mail: jayach2003@rediffmail.com

Date of Submission: 18/01/2014.

Date of Peer Review: 19/01/2014.

Date of Acceptance: 24/01/2014.

Date of Publishing: 30/01/2014. 